\title{
The use of fully-covered self-expanding metallic stents for intra- procedural management of post-sphincterotomy perforations: a single-center study (with video) $\square$
}

(1) $\odot$

\author{
Authors \\ Guru Trikudanathan, Patrick Hoversten, Mustafa A. Arain, Rajeev Attam, Martin L. Freeman, Stuart K Amateau
}

Institution

Division of Gastroenterology, University of Minnesota, Minneapolis, United States

submitted 2.8.2017

accepted after revision 9.10.2017

Bibliography

DOI https://doi.org/10.1055/s-0043-121884 |

Endoscopy International Open 2018; 06: E73-E77

(c) Georg Thieme Verlag KG Stuttgart · New York

ISSN 2364-3722

Corresponding author

Stuart K Amateau, MD, PhD, Chief of Endoscopy, Assistant Professor of Medicine, Division of Gastroenterology, 406 Harvard St SE, MMC36, Minneapolis, MN 55455, USA

Fax: +1-612-625-5620

amateau@umn.edu

\section{ABSTRACT}

Background and study aims Management of postsphincterotomy perforations is variable, with some patients managed conservatively and other requiring surgery. Fullycovered self-expanding metal stents (FCSEMs) have been used in the past, but data is limited. The aim of this study was to report the clinical characteristics and outcomes fol- lowing placement of anchored FCSEMSs for the immediate management of post-sphincterotomy perforation.

Patients and methods All patients undergoing an ERCP procedure between June 2011 and December 2015 at our institution were reviewed for post-sphincterotomy perforation. All intra-procedurally recognized perforations underwent placement of FCSEMs with flexible anchoring fins and were included in this study. Data extracted included patient demographics, indication, peri-procedural details, clinical course and long-term outcome following anchored FCSEMS placement.

Results A total of 15 patients ( 12 females, median age-66 years) with post-sphincterotomy perforation were included. Major indications included choledocholithiasis in 9 $(60 \%)$, and 5 (33.3\%) patients had intra-ampullary or periampullary diverticula. All patients underwent placement of FCSEMS without any complication and had immediate resolution of perforation as evidenced by decrease in fluoroscopic gas and lack of contrast extravasation. None of the patients became symptomatic or needed surgery with a median 2 days of hospitalization following the procedure. Stents were removed after a median of 30.5 days and no complications were noted during follow-up after stent removal.

Conclusions Anchored FCSEMs are safe and effective for management of intra-procedurally recognized post-sphincterotomy perforations and obviates need for surgery.

\section{Introduction}

Perforation is one of the most dreaded complications of endoscopic retrograde cholangiopancreatography (ERCP), which if unrecognized or untreated is associated with a relatively high morbidity and mortality [1-4]. ERCP-related perforations are formally categorized using the Stapfer classification system which incorporates the mechanism, location and severity of perforations [5]. Among these, Stapfer type II perforations (periampullary perforations of the medial wall of the duodenum) associated with biliary or pancreatic sphincterotomy or precut sphincterotomy, represent the most frequent type of perforation, comprising anywhere from $15 \%$ to $68 \%$ of all cases [5-7]. Post sphincterotomy perforation occurs in $0.3-1.3 \%$ of ERCP procedures with a relatively high mortality rate of $7 \%$ to $14 \%[1-4,8]$. Currently there is no consensus regarding management of post-sphincterotomy perforations as their incidence is very low and the clinical consequences vary enormously [9]. While some experts advocate a conservative approach based on the clinical course, others favor upfront surgical repair, given the complications associated with delayed operative intervention $[10,11]$. Traditional management consists of close monitoring and the diversion of gastric, duodenal, and biliary fluid through nasogastric tubes, naso-duodenal tubes, and 
endoscopic naso-biliary tubes, respectively [7]. A few reports showed the safe and effective use of metallic endoclips in the closure of sphincterotomy related duodenal perforations [10, $12,13]$. Plastic stents have been used for treatment of postsphincterotomy perforations, but their limited diameter may fail to completely manage the underlying problem [14]. Fullycovered self-expanding metal stents (FCSEMs) have been suggested for management of post-sphincterotomy perforations, as the covered wide-caliber stent can provide complete sealing of the defect, while the stent lumen enables physiologic drainage of bile and thus prevent additional fluid leakage. Data regarding the latter approach, is restricted to a few patients mostly after delayed presentation $[14,15]$. Our hypothesis is that immediate short-term stenting of post-sphincterotomy perforations with FCSEMs when recognized during the initial ERCP procedure facilitates quicker recovery and obviates need for surgery. The aim of our study was to report the outcomes of the use of an anchored nitinol fully-covered self-expanding metal stent for management of these post-sphincterotomy perforations.

\section{Patients and methods}

All patients who underwent ERCP at our institution between June 2011 and December 2015 were reviewed for post-sphincterotomy perforation. All endoscopic complications were collected prospectively during the interval by an online reporting system, with every member of the endoscopy faculty, consult service attending, and nursing staff having access to enter complications. All intra-procedural perforations underwent placement of a biliary FCSEM with flexible anchoring fin and were included in this study. Demographic characteristics of the patients, indication for the procedure, findings at ERCP, endoscopic and radiographic findings of the sphincterotomy related perforation, post-procedure course including SIRS following procedure (fever $>100.4$, heart rate $>90$, respiratory rate $>20$ or $\mathrm{Paco}_{2}<32 \mathrm{mmHg}$ or $\mathrm{WBC}>12,000$ or $<4000$ ), length of post-procedural hospital stay, and timing of the subsequent ERCP were retrospectively extracted. Presence or absence of a gallbladder and the relationship of the anchored FCSEM to the cystic take-off was noted. In addition, development of other ERCP-related adverse events (AEs) were classified according to the consensus guidelines [16].

\section{Definitions}

Endoscopic sphincterotomy perforation was defined as presence of free intraperitoneal or retroperitoneal air visualized fluoroscopically during or immediately after sphincterotomy, with or without obvious full-thickness defect above the upper margin of the bile duct, and/or extraluminal contrast extravasation at the sphincterotomy site.

\section{Procedural details}

All ERCP procedures were performed under general anesthesia by experienced endoscopists (MA, RA, MF and SA) who had each performed $>2500$ procedures. Standard video duodenoscopes (TJF-160/180 series, Olympus America Inc., Center Val- ley, Pennsylvania, USA) were utilized with carbon dioxide $\left(\mathrm{CO}_{2}\right)$ for insufflation. All sphincterotomies were performed using the new generation microprocessor-controlled electrosurgical generator (ERBE, ERBE USA). If there was a strong suspicion of sphincterotomy-related perforation using the above definition, they were immediately treated by placement of biliary fully covered self-expanding metal stent. In addition, if the distal bile duct was felt to be sufficiently small caliber to risk compression of the pancreatic orifice by the FCSEMS or if the patient was considered at moderate to high risk of post-ERCP pancreatitis, a pancreatic stent was prophylactically placed prior to deployment of the FCSEMS. Pancreatic stents used were $4 \mathrm{Fr} \times 11 \mathrm{~cm}$ soft material unflanged stents (Freeman-Hobbs stent, Hobbs Medical) or $5 \mathrm{Fr} \times 3 \mathrm{~cm}$ Sofflex stents (Cook Medical, WinstonSalem, NC). Biliary FCSEMS were 10-mm luminal diameter ranging from $4 \mathrm{~cm}$ to $8 \mathrm{~cm}$ in length with anti-migratory properties involving anchoring fins (Viabil, Conmed, Utica, New York, United States) and were deployed in a transpapillary fashion (as shown in $\nabla$ Video 1 ). When the gallbladder was in situ, FCSEMs were placed below the cystic-duct insertion or FCSEMSs with upstream fenestrations were used to avoid cystic duct obstruction. All patients were admitted overnight for observation. All were scheduled for second ERCP during which the FCSEMSs were removed with either a rat-toothed forceps or cold snare. The stent was usually withdrawn through the instrument channel or by withdrawing the duodenoscope with the stent in tandem. After stent removal, an occlusion cholangiogram was performed to confirm the resolution of the post-sphincterotomy perforation. Long-term follow-up was performed by reviewing clinical notes during subsequent clinic visits and available laboratory results and imaging performed weeks to months after stent removal.

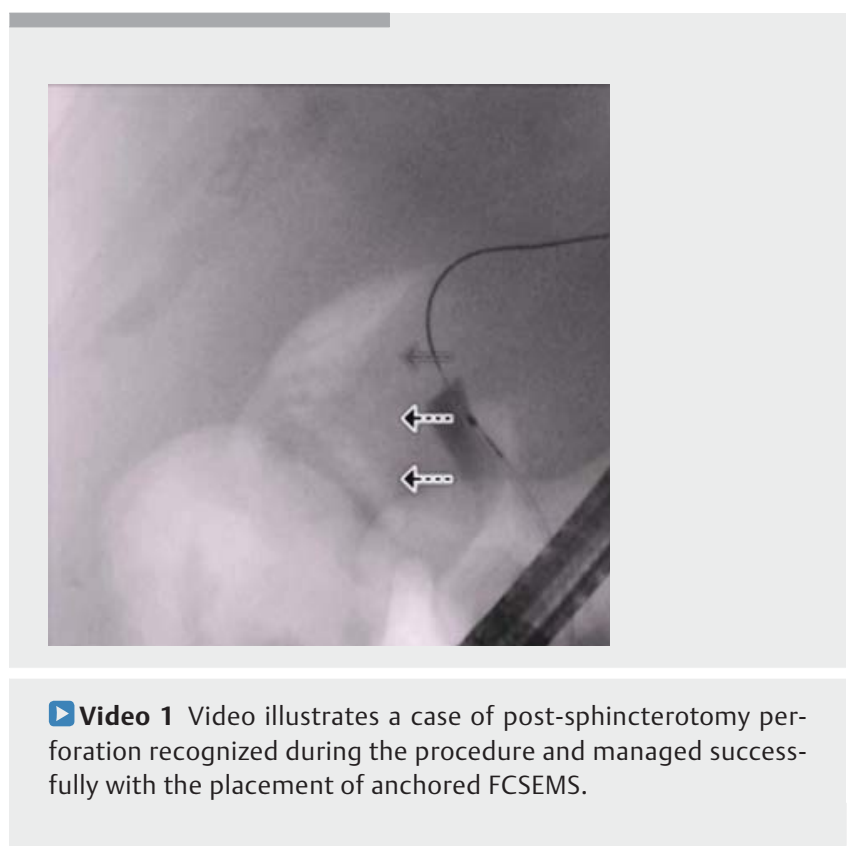


- Table 1 Patient demographics and baseline characteristics.

\begin{tabular}{|l|c|}
\hline No of patients included & 15 \\
\hline Sex (male/female) & $3 / 12$ \\
\hline Age median (range) in years & $66(20-96)$ \\
\hline White & $12(80 \%)$ \\
\hline ASA physical status & \\
\hline ASA I & $1(6.7 \%)$ \\
\hline ASA II & $10(66.7 \%)$ \\
\hline ASA III & $4(26.7 \%)$ \\
\hline Indication for ERCP & \\
\hline Bile duct stone & $9(60 \%)$ \\
\hline Suspected SOD & $4(26.7 \%)$ \\
\hline Benign biliary stricture & $1(6.7 \%)$ \\
\hline Post-cholecystectomy leak & $1(6.7 \%)$ \\
\hline Anomalous anatomy & \\
\hline Periampullary diverticulum & $5(33.3 \%)$ \\
\hline Roux-en-Y gastric bypass & $1(6.7 \%)$ \\
\hline Type of sphincterotomy (initial/extension/pre-cut) & $13 / 2 / 1$ \\
\hline ERCP, endoscopic retrograde cholangiopancreatography; SOD, sphincter of \\
\hline Oddi dysfunction
\end{tabular}

\section{Results}

A total of 4860 ERCP procedures, including 1784 initial or extension biliary sphincterotomies were performed during the study period. During the study period, fifteen patients (females 12 [ $80 \%$ ], male 3 [20\%] and median age 66 years) were recognized with post-sphincterotomy perforations at the time of ERCP. None of the 1784 sphincterotomy patients had delayed recognition of perforation. Most patients were ASA II status, though some were ASA I and III. The baseline characteristics of these patients have been summarized in $>$ Table 1 .

In patients with perforations, the most common indication for ERCP was bile duct stone extraction (60\%), followed by sphincter of Oddi dysfunction (26.7\%) and other indications (13\%). Extension of previous sphincterotomy was performed in 2 of the 15 patients (13.3\%). A difficult or failed cannulation by standard technique was encountered in 3 (20\%) of the patients with one patient needing pre-cut (free-hand needle-knife) sphincterotomy and two patients needing EUS guided rendezvous for access to bile duct. Peri or intra-diverticular papillae were encountered in 5 (33.3\%) of the patients. Lengths of the stent deployed were $4 \mathrm{~cm}$ ( 2 patients), $6 \mathrm{~cm}$ (10 patients) and 8 cm (3 patients).

The median length of stay in the entire cohort was 2 days. SIRS response was witnessed in only 1 patient (6.7\%) within 48 hours after the procedure and no patients developed sepsis related complications or post ERCP pancreatitis or cholecystitis (as shown in $>$ Table 2). The stents were left for a median dura-
- Table 2 Procedure outcomes following placement of anchored FCSEM.

\begin{tabular}{|l|c|}
\hline Procedure-related adverse events, $\mathbf{n}(\%)$ & \\
\hline Post-ERCP pancreatitis & 0 \\
\hline Cholangitis & 0 \\
\hline Post-ERCP cholecystitis & 0 \\
\hline Death & 0 \\
\hline Median (range) length of hospital stay in days & $2(0-10)$ \\
\hline Median (range) duration in days of stent placement & $30.5(14-45)$ \\
\hline Median follow-up in days after stent removal & 150 \\
\hline
\end{tabular}

tion of 30.5 days (range 14 to 45 days) and were all retrieved without any complications such as fracture, stent migration or tissue ingrowth. The median follow-up after stent removal was 150 days. None of the patients developed any late complications after stent removal.

\section{Discussion}

ERCP has evolved from a diagnostic to a therapeutic modality for biliary and pancreatic disease. The increase in volume and complexity of these procedures has led to an increase in number and spectrum of complications [8]. Post-sphincterotomy perforations caused by extension of a sphincterotomy incision beyond the intramural portion of the bile or pancreatic duct is classically associated with high morbidity and mortality. Although some experts favor conservative management, a recent systematic review of 11 studies showed that after initial nonsurgical management, surgery was needed in 29/137 (21\%) of patients with Stapfer type II perforation with a mortality of $38 \%$ in those undergoing delayed surgery [17]. It was reasoned that operative interventions for perforations, when delayed, become technically more challenging because of adhesions and loss of tissue planes and was associated with higher mortality $[11,17,18]$. Thus, optimal management for post sphincterotomy perforations remains contentious. If the appropriate expertise and equipment is available, endoscopic closure has been shown to obviate surgical intervention [19]. Endoscopic closure using hemostatic endoscopic clips or an over-the-scope clipping device has been described $[10,12,13]$. However, deployment of these clips to seal medial wall perforation is technically challenging with the duodenoscope [20]. Moreover, over-the-scope clips cannot be reproducibly applied because of angulation and difficult access with a potential risk for closing the ampullary orifice [20]. Placement of stents across the sphincterotomy site results in mechanical occlusion of the perforation site facilitating free flow of bile into the duodenum, thus minimizing the risk of bacterial translocation and peritonitis [17]. FCSEMs are preferred over plastic stents or naso-biliary drains since they provide larger caliber for complete sealing of the perforation defect and the stent lumen may facilitate physiologic drainage of bile to prevent additional fluid leakage 
[17]. In our study, we demonstrated that the immediate intraprocedural deployment of anchored FCSEMs for a short term completely obviates the need for surgery in all the patients and was associated with no added morbidity or mortality.

During our study period (June 2011 to December 2015), a total of 4860 ERCP procedures were performed, with 1784 (initial or extension) sphincterotomies performed. Post sphincterotomy perforations were recognized intra-operatively in 15 patients $(0.8 \%)$ and all were managed with placement of a anchored FCSEM. Difficult cannulation was encountered in 3 of the 15 patients ( $20 \%$ ) with 2 of the patients needing EUS-guided rendezvous procedure to obtain biliary access and one patient needing pre-cut traction sphincterotomy, the latter a recognized risk factor for post sphincterotomy perforation [1, 6 , $8,21]$. The presence of peri or intra-diverticular papilla was again shown to be a significant risk factor for perforation, which is consistent with prior studies [8]. Type 2 sphincter of Oddi dysfunction was the indication in $26.7 \%$ of the ERCP procedures and itself is a recognized risk factor for Stapfer type II perforation as the goal is complete ablation of the sphincter muscle [21]. Another observation was that 4 (26.6\%) of our patients had concomitant post sphincterotomy bleeding, which was managed by immediate subepithelial injection of $(1: 10,000)$ epinephrine prior to stent deployment. This is consistent with another Turkish study, which reported an incidence of $15 \%$ of sphincterotomy related bleeding. However, none of our patients developed post ERCP pancreatitis in contrast to the $15 \%$ reported in the same study. This can be attributed to our placement of prophylactic pancreatic duct stents in eleven (73.3\%) of our patients along with adjuvant rectal indomethacin administration in all appropriate patients. Although 6/15 $(40 \%)$ had a gallbladder in situ at the time of placement of the FCSEM, none developed cholecystitis. This was not surprising as FCSEMs with upstream fenestrations were placed in these patients below the cystic duct insertion to specifically avoid cystic duct obstruction.

We believe early recognition of the post-sphincterotomy perforation, use of $\mathrm{CO}_{2}$ for insufflation and prompt management with fully-covered stent placement were critical for our successful outcomes. It can be argued that these patients could have had a similar outcome if subjected to conservative management. However, given the existing literature and our patient population with a median age of 66 years, 14 of the 15 patients having multiple comorbid conditions (ASA II and III) and the unpredictable course of conservative management, we thought it prudent to place these stents during the procedure. Patients resumed oral feeds and were discharged rapidly from the hospital, and FCSEM removal, which occurred after a median duration of 30.5 days, was performed on an outpatient basis. The cost of these stents should be weighed against the risk of prolonged hospitalization and possible intensive care requirements and potential subsequent need for surgery. There were no complications related to insertion or removal of the FCSEMs. Stent migration or tissue hyperplasia noted in other related studies was not seen in our series and none of our stents fractured $[14,15]$.The purpose of the anchored FCSEMs is to provide the radial force to occlude the perforation site, allowing expedited healing and the anchoring fins prevented migration of the stent. The potential complication of stent related sludge formation and reflux of gastroduodenal contents should prompt close follow up and removal of FCSEMs in a timely fashion.

Limitations of the study include the retrospective nature of the study design and lack of a control arm. As this is our practice for management of all sphincterotomy perforation and we were exploring the role of immediate stent placement, a control arm was not feasible. The sample size for our study was relatively small, but considering the $0.3 \%$ to $1 \%$ incidence of ERCP-related perforations, with only half being represented by post-sphincterotomy perforation, our sample size is reasonable. Moreover, this is the largest study to date investigating the role of intraprocedural anchored FCSEMs placement for the management of this complication.

\section{Conclusion}

In conclusion, our study shows that post-sphincterotomy perforations when promptly recognized and immediately managed with placement of anchored FCSEMs prevented significant complications such as SIRS, or development of major extraluminal complications. There was no need for surgery or other invasive interventions and outcomes were acceptable. Given the low incidence of post-ERCP perforations, our findings need to be further validated though multicenter, prospective studies, before recommending routine placement of these stents to manage post-sphincterotomy perforations.

\section{Competing interests}

Dr. Freeman is a consultant for Boston Scientific, Cook Medical, XLumena Corp, and Neometrics. Dr. Amateau is a consultant for Boston Scientific, US Endoscopy and Merit Endoscopy and a research collaborator with Cook Medical

\section{References}

[1] Freeman ML, Nelson DB, Sherman S et al. Complications of endoscopic biliary sphincterotomy. N Engl J Med 1996; 335: 909-918

[2] Christensen M, Matzen P, Schulze $S$ et al. Complications of ERCP: a prospective study. Gastrointest Endosc 2004; 60: 721 - 731

[3] Loperfido S, Angelini G, Benedetti G et al. Major early complications from diagnostic and therapeutic ERCP: a prospective multicenter study. Gastrointest Endosc 1998; 48: 1- 10

[4] Masci E, Toti G, Mariani A et al. Complications of diagnostic and therapeutic ERCP: a prospective multicenter study. Am J Gastroenterol 2001; 96: $417-423$

[5] Stapfer M, Selby RR, Stain SC et al. Management of duodenal perforation after endoscopic retrograde cholangiopancreatography and sphincterotomy. Ann Surg 2000; 232: 191 - 198

[6] Enns R, Eloubeidi MA, Mergener $\mathrm{K}$ et al. ERCP-related perforations: risk factors and management. Endoscopy 2002; 34: 293 - 298

[7] Odemis B, Oztas E, Kuzu UB et al. Can a Fully Covered Self-Expandable Metallic Stent be Used Temporarily for the Management of Duodenal 
Retroperitoneal Perforation During ERCP as a Part of Conservative Therapy?. Surg Laparosc Endosc Percutan Tech 2016; 26: e9-e17

[8] Fatima J, Baron TH, Topazian MD et al. Pancreaticobiliary and duodenal perforations after periampullary endoscopic procedures: diagnosis and management. Arch Surg Chi III 1960 2007; 142: 448-454; discussion 454-455

[9] Vezakis A, Fragulidis G, Nastos C et al. Closure of a persistent sphincterotomy-related duodenal perforation by placement of a covered self-expandable metallic biliary stent. World J Gastroenterol 2011; 17 : $4539-4541$

[10] Katsinelos P, Paroutoglou G, Papaziogas B et al. Treatment of a duodenal perforation secondary to an endoscopic sphincterotomy with clips. World J Gastroenterol 2005; 11: 6232-6234

[11] Chaudhary A, Aranya RC. Surgery in perforation after endoscopic sphincterotomy: sooner, later or not at all? Ann R Coll Surg Engl 1996; 78: $206-208$

[12] Baron TH, Gostout C], Herman L. Hemoclip repair of a sphincterotomy-induced duodenal perforation. Gastrointest Endosc 2000; 52: $566-568$

[13] Amodio PM, Faggiani R, Pastorelli A et al. Selected treatments for duodenal perforation after ERCP. A report of three cases. Chir Ital 2007; 59: $343-346$
[14] Irani S, Baron TH, Law R et al. Endoscopic treatment of nonstricturerelated benign biliary diseases using covered self-expandable metal stents. Endoscopy 2015; 47: 315-321

[15] Canena J, Liberato M, Horta D et al. Short-term stenting using fully covered self-expandable metal stents for treatment of refractory biliary leaks, postsphincterotomy bleeding, and perforations. Surg Endosc 2013; 27: $313-324$

[16] Cotton PB, Lehman G, Vennes J et al. Endoscopic sphincterotomy complications and their management: an attempt at consensus. Gastrointest Endosc 1991; 37: 383 - 393

[17] Vezakis A, Fragulidis G, Polydorou A. Endoscopic retrograde cholangiopancreatography-related perforations: Diagnosis and management. World J Gastrointest Endosc 2015; 7: 1135-1141

[18] Bell RC, Van Stiegmann G, Goff ] et al. Decision for surgical management of perforation following endoscopic sphincterotomy. Am Surg 1991; $57: 237-240$

[19] Balmadrid B, Kozarek R. Prevention and management of adverse events of endoscopic retrograde cholangiopancreatography. Gastrointest Endosc Clin N Am 2013; 23: 385 - 403

[20] Baron TH, Wong KeeSong LM, Zielinski MD et al. A comprehensive approach to the management of acute endoscopic perforations (with videos). Gastrointest Endosc 2012; 76: 838 - 859

[21] Kumbhari V, Sinha A, Reddy A et al. Algorithm for the management of ERCP-related perforations. Gastrointest Endosc 2015; 83: 934 - 43 